\title{
Será a Nigéria um Estado falhado? o grupo Boko Haram
}

Is Nigéria a failed state?

The Boko Haram group

\section{Introdução}

Apesar de ser o maior produtor de petróleo da África, a Nigéria continua sofrendo de problemas estruturais que impedem o desenvolvimento do país e empurram cada vez mais a sua população para a pobreza. A fragilidade das instituições, a corrupção, as divergências étnicas e religiosas e a ausência de serviços básicos, a que se associa a degradação ambiental e os problemas de gestão, têm provocado o descontentamento da população contra o Estado nigeriano e contribuem para agravar as más condições de vida da população.

A Nigéria tem ainda graves problemas de segurança, em especial nos estados do Norte, com a atuação do grupo Boko Haram, que reivindica a instauração de um Estado Islâmico governado pela Sharia, a lei islâmica. O incremento do fundamentalismo islâmico

1 É doutora em Ciência Política e Relações Internacionais desde 2002. É professora auxiliar no Departamento de História e Estudos Políticos Internacionais da Faculdade de Letras da Universidade do Porto. Coordenadora do livro The European Union Neighborhood: challenges and opportunities (Asghate, 2013). Autora de vários artigos internacionais, tais como: Albania's Difficult Path Towards Democracy (Canadian American Slavic Studies Journal, v. 48, n. 4, 2014); Civil Society in Macedonia's Democratization Process (Journal of Contemporary European Studies, v. 21, n. 2, 2013); Public Administration in Macedonia's Democratization Process (Journal of Communist and Post-Communist Studies, v. 48, n. 4, 2013). E-mail: <tcierco@letras.up.pt>.

2 É oficial de polícia com a categoria de intendente. Mestre em Relações Internacionais pela Universidade da Beira Interior desde 2014 e também em Comportamentos Desviantes e Ciências Criminais pela Faculdade de Medicina da Universidade de Lisboa desde 2008. E-mail: <agomesbelo@gmail.com>. 
e da violência, sobretudo na parte Norte do país, evidencia a fragilidade das instituições políticas, principalmente a nível securitário, e a ausência de uma resposta capaz por parte das autoridades governamentais.

Isso nos leva a questionar se a Nigéria poderá ser considerada um Estado falhado. E, tratando-se de um Estado falhado em que a segurança interna é deficitária e os conflitos interétnicos proliferam, estará a unidade nacional comprometida ou seriamente ameaçada? Podemos, desta forma, tentar aferir até que ponto o fundamentalismo islâmico tem afetado o desenvolvimento humano e econômico na Nigéria e de que forma o governo tem tentado resolver o problema.

Este artigo está dividido em quatro partes. Na primeira parte, procede-se à conceitualização do Estado e das suas funções, enquadrando teoricamente a análise do tema no conceito de Estado "falhado". Na segunda parte, faz-se uma caracterização geral da Nigéria, destacando os conflitos étnico-religiosos que estão na base da atual instabilidade do Estado. Nesta parte, argumenta-se que a incapacidade governamental em resolver os problemas básicos da população e em garantir a sua segurança deu origem à revolta e ao aparecimento de grupos que procuram substituir o Estado no cumprimento de algumas das suas funções essenciais. $\mathrm{Na}$ terceira parte, caracteriza-se um destes grupos extremistas existentes na Nigéria, o grupo Boko Haram, que tem desestabilizado, nos últimos anos, o país a nível político, econômico e social, criando divergências e conflitos entre várias etnias e religiões, pondo em causa a unidade e o desenvolvimento nacional. Por fim, na última parte, analisa-se a forma como o governo tem gerido e tentado resolver esse problema que questiona a autoridade e a legitimidade do Estado.

\section{Nigéria: Estado falhado?}

Atualmente a Nigéria enfrenta um desafio ao nível da segurança interna. O incremento do fundamentalismo islâmico no Norte do país, a violência protagonizada pelo grupo Boko Haram 
e a consequente insegurança da população evidenciam a incapacidade do Estado em assegurar e garantir a estabilidade do país.

Normalmente, o conceito de Estado corresponde a uma sociedade politicamente organizada, fixada em um território, dispondo de um poder institucionalizado para satisfazer os interesses gerais dos seus membros. Segundo Marcelo Caetano (2014, p. 16), entende-se por Estado "um povo, fixado num território de que é senhor, e que institui, por autoridade própria, órgãos que elaboram as leis necessárias à vida colectiva e impõem a sua respectiva execução”. De acordo com Marcelo Rebelo de Sousa (1978, p. 108), podemos entender o Estado como "um povo fixado num determinado território que institui por autoridade própria, dentro desse território, um poder político relativamente autónomo". A existência do Estado pressupõe a organização política de um povo que controla soberanamente um território com o principal objetivo de assegurar o bem-estar social da coletividade. O Estado existe porque a sociedade acredita que sem ele não é possível manter a paz interna e assegurar a defesa externa. Assim, a segurança das pessoas e dos valores é uma das primeiras finalidades do Estado. Mas a paz só é durável se assentar em relações de respeito mútuo, sendo que a segunda finalidade do Estado será a manutenção da justiça. Compete também ao Estado promover, total ou parcialmente, a satisfação de necessidades materiais e espirituais das pessoas e dos grupos sociais (terceira finalidade do Estado) - promoção do bem-estar social. O Estado tem, assim, funções de segurança, justiça e de bem-estar, e a responsabilidade de dar resposta às necessidades básicas e legítimas dos seus cidadãos. No entanto, no sistema mundial, alguns Estados não são capazes de o fazer. A corrupção, a criminalidade, as profundas desigualdades sociais e a discriminação institucional são apenas alguns dos indicadores que identificam um Estado falhado. O fato de o Estado ser incapaz de garantir a segurança, a educação, a saúde, as infraestruturas básicas e o bem-estar da sua população pode levar à revolta e à procura por alternativas que possam assegurar e garantir o cumprimento de algumas das suas funções. 
A fragilidade do Estado nigeriano está relacionada ao passado colonial e à sua história de confrontos regionais e étnico-religiosos, com a pobreza da população, a má governação, a corrupção das elites, a degradação ambiental, o subdesenvolvimento das infraestruturas, a criminalidade e a instabilidade política, entre outros (Aljazeera, 2015). Essa situação tem criado grupos de cidadãos descontentes que procuram alternativas ao Estado, aderindo ao grupo Boko Haram.

De acordo com o Índice de Estados Falhados referente a 2015, a Nigéria surge em $14^{\circ}$ lugar entre 178 países analisados (Foreign Policy, 2015). Segundo Robert Rotberg (2003, p. 1), o conceito de Estado falhado implica a análise de alguns aspectos centrais. Os Estados são considerados "falhados" quando são "consumidos por violência interna e deixam de fornecer um serviço político positivo aos seus cidadãos". A primeira função do Estado consiste em garantir a segurança dentro do território (op. cit., p. 3). A partir do momento em que a segurança está garantida, outros serviços podem também ser acautelados junto da população, tais como a salvaguarda do Estado de direito, a participação política, os serviços básicos de educação e saúde.

Entre os indicadores de um Estado falhado encontram-se a perda de controle sobre o território, a instabilidade e a violência e a ausência de bem-estar da população. A avaliação do Estado é assim efetuada em relação a três das suas funções básicas: representação, segurança e preocupação com as necessidades básicas da população (Milliken e Krause, 2002, p. 756). Os Estados fragilizados podem perder o monopólio do cumprimento de algumas das suas funções, nomeadamente a de segurança (Risse, 2013, p. 9). Como é apontado por Christian Lund (2006, p. 686), a luta de um Estado para cumprir as suas obrigações pode levar a que um grupo de atores informais acabe por se substituir ao Estado, prestando serviços básicos à população. A ausência do Estado não se traduz, assim, em um vácuo (Titeca e Herdt, 2011, p. 230). No entanto, os interesses particulares destes atores podem acabar por colocar em causa não só a qualidade dos serviços prestados, como 
também o Estado de direito ou a representação política, dando lugar à corrupção e ao nepotismo.

No seu papel tradicional enquanto guarda da segurança, o Estado é responsável pela proteção do território nacional e das instituições nacionais. Em um mundo globalizado em que os problemas de segurança dificilmente podem ser contidos nas fronteiras de um único Estado (Jackson e Sorensen, 2007, p. 274-273), a ausência de segurança nacional pode transformar-se em um problema de segurança internacional que interliga os Estados falhados com o fenômeno do terrorismo. Estados fragilizados, com instituições caracterizadas pela corrupção, são considerados "paraísos seguros" para os terroristas poderem prosseguir com as suas intenções criminosas.

\section{Breve caracterização geopolítica da Nigéria}

Em termos gerais, conseguem-se identificar na Nigéria alguns indicadores de Estado falhado (Hamzat, 2015; Ifowodo, 2009). Por um lado, a pobreza e a corrupção generalizada, fenômenos que se mantêm desde a época colonial, mas que se acentuaram após a independência política do país, refletem a ausência de autoridade e de liderança por parte do Estado. Por outro lado, a permanência de conflitos étnico-religiosos que mostram não só a fragilidade das instituições, como também a incapacidade do Estado em encontrar uma solução para esse clima de grande instabilidade e de insegurança.

O crescimento da economia do petróleo tem-se revelado uma bênção e uma maldição para a Nigéria. Apesar de o petróleo traduzir-se em receitas e potencial de crescimento econômico para o país, apenas uma minoria beneficia-se dessa riqueza. ${ }^{3} \mathrm{~A}$ maioria da população na Nigéria contínua pobre. Os indicadores de pobreza, como a mortalidade infantil e maternal, a má-nutrição, o acesso à água e ao saneamento e a esperança média de vida mostram um

3 A grande dependência do petróleo (75\% das receitas e 14\% do Produto Nacional Bruto) continua a ser um dos grande desafios econômicos do país (Nações Unidas, 2014, p. 1). 
sinal de deterioração nos últimos anos. ${ }^{4}$ Os problemas ambientais são também graves, particularmente na região do Delta do Níger, em que as atividades de exploração de petróleo e sua extração provocaram danos ambientais e comprometeram os tradicionais meios de subsistência da população (Onwuka, 2005, p. 655-656).

O Relatório do Programa das Nações Unidas para o Desenvolvimento (Pnud) (Nações Unidas, 2006, p. 35) sobre o desenvolvimento humano no Delta do Níger refere que "a critical issue in the Delta is not only the increasing incidence of poverty, but also the intense feeling among people that they ought to do far better given the enormous resources flowing from their region". Segundo esta organização:

poverty has become a way of life due to economic stagnation, unemployment, poor quality of life due to shortages of essential goods and facilities, an unhealthy environment and government insensitivity... Poverty in the Niger Delta region encompasses the issues of discrimination, neglect and the lack of a voice. Oil wealth enriches Nigeria as a country, but it has not alleviated the grinding poverty, neglect and deprivation in the region that produces it (Nações Unidas, 2006, p. 36-37).

Os longos períodos de seca, a infertilidade dos solos, a iliteracia, a fome, a ausência de saneamento, a baixa produtividade, a corrupção e o desemprego são algumas das causas da pobreza na Nigéria (Adawo, 2011, p. 15).

Para além desse grave problema social, a Nigéria é ainda classificada pela Transparency International (2015) como um dos países mais corruptos do mundo. Em 2014, o Índice de Perceção da Corrupção colocou a Nigéria em 136 lugar entre 175 países auscultados ao nível da corrupção do setor público. De acordo com Onigu Otite (2000, p. 10), a corrupção na Nigéria pode ser dividida em cinco grupos: política, econômica, burocrática,

4 De acordo com o Programa das Nações Unidas para o Desenvolvimento (Pnud) de 2014, a Nigéria tem uma taxa de 62,6\% de pobreza (Nações Unidas, 2014). 
judicial e moral. Em termos práticos, manifesta-se na inflação de contratos, na troca de comissões, nas fraudes e nas falsificações de contas nos serviços públicos, na negligência, na utilização de subornos, na perversão da justiça e da Polícia, em burlas relacionadas com o comércio externo, contrabando, lavagem de dinheiro e envio deste para paraísos fiscais (Ike, 2009, p. 10-11). A fraca liderança do país promove esse ambiente de corrupção generalizada, com efeitos negativos no processo de desenvolvimento do país (Edewor, 2011, p. 87-88).

Em termos sociais, a Nigéria é o país mais populoso da África Subsariana e personifica uma afinidade e uma diversidade histórica, cultural, étnica, religiosa, social e linguística relevante. ${ }^{5} \mathrm{O}$ espetro religioso é altamente complexo e dinâmico, compreendendo duas religiões principais, o Cristianismo e o Islão, e uma multiplicidade de tradições religiosas, incluindo religiões indígenas e movimentos espirituais. ${ }^{6}$ Segundo o Pew Research Center (2012), em 2010, a porcentagem de cristãos na Nigéria era de $49,3 \%$ e a de muçulmanos era de $48,8 \%$, pertencendo o restante a outras religiões, como o Budismo e o Hinduísmo. Estes dois grupos religiosos são os mais representativos na Nigéria. No que diz respeito à sua dispersão territorial, o Norte do país é predominantemente muçulmano, ao passo que o Sul é cristão.

Segundo Idowu-Fearon (2005, p. 1), a Nigéria está dividida em seis zonas geopolíticas em que coexistem uma multiplicidade de grupos étnicos e a aparente competição entre o Cristianismo e o Islão acentua essa divisão, ditando também a sua evolução política e econômica. A Norte domina a política, ao passo que a Sul domina a economia. A consequência imediata é que o Sul é pró-ocidental, enquanto o Norte é antiocidental e pró-muçulmano (Idowu-Fearon, 2005). Segundo o Relatório de Desenvolvimento Humano elaborado pelas Nações Unidas (Nações Unidas,

A população da Nigéria é composta por mais de 200 grupos étnicos e 500 línguas indígenas.

6 Cerca de $50 \%$ da população nigeriana é muçulmana sunita, estando mais concentrada nas savanas a Norte, onde o Islão apareceu entre os séculos XI e XIV. Os cristãos representam 40\% da população e estão mais concentrados no Sul e no Centro do país (Falola e Heaton, 2008, p. 4). 
2008, p. 32), a Zona Norte do país, maioritariamente muçulmana, apresenta piores índices econômicos quando comparada à Zona Sul. O Produto Interno Bruto (PIB) per capita dos estados do Sul do país é superior aos da Zona Norte, principalmente os situados no Nordeste da Nigéria, o que pode ser explicado pela exploração petrolífera ali concentrada. Segundo o mesmo relatório (Nações Unidas, 2008, p. 64), a incidência da pobreza é maior na Zona Norte do país.

A religião representa o meio por meio do qual muitos nigerianos procuram compreender a realidade e, ao mesmo tempo em que se apresenta como um instrumento de paz e coesão, também fomenta a violência religiosa e o conflito no país (Adogame, 2010, p. 479).

Nos últimos anos, a Nigéria tem sido alvo de sucessivas ações terroristas de cariz islâmico que ameaçam a segurança da população. O advento da democracia em 1980 e a passagem das regiões a estados fez emergir o uso da religião para fins políticos. A maior manipulação desse fenômeno deu-se com a implantação da Sharia nos estados do Norte, considerado pelos cristãos como o ponto de partida para a gradual islamização do país. ${ }^{7}$

Os estados do Norte tornaram-se o lugar ideal para crises religiosas e étnicas, com a discriminação dos cristãos. Essa situação provocou a deslocação de uma parte da população, o aumento dos refugiados e a diminuição da representação cristã na vida política e econômica no Norte do país. De acordo com Idowu-Fearon (2005, p. 9), o Cristianismo e o Islão, apesar de terem contribuído para o crescimento do país, também estão na base da violência.

A religião tem sido um componente inseparável da política na Nigéria. Os mais recentes acontecimentos de extremismo

7 A Sharia representa o corpo da lei religiosa islâmica. O termo significa "caminho para a fonte" ou "rota para a fonte [de água]", e é a estrutura legal dentro da qual os aspectos públicos e privados da vida do adepto do Islamismo são regulados, tanto para aqueles que vivem sob um sistema legal baseado na figh (os princípios islâmicos da jurisprudência) quanto para os muçulmanos que vivem fora do seu domínio. A Sharia lida com diversos aspectos da vida cotidiana, bem como a política, a economia, os bancos, os negócios, os contratos, a família, a sexualidade, a higiene e as questões sociais. 
étnico-religioso refletem problemas políticos e sociais complexos. $\mathrm{O}$ descontentamento em vários setores da sociedade nigeriana provoca confrontos violentos de caráter étnico e religioso que questionam a interpretação da estrutura federal. O Norte empobrecido, que alimenta a rivalidade entre muçulmanos e cristãos, encontra-se alienado do governo de Abuja. Os níveis de violência e oposição contra o Estado constituem terreno fértil para a Al-Qaeda recrutar operacionais nigerianos.

A religião tem também desempenhado um papel importante no desenvolvimento político do país. Constitui não só uma ligação indispensável entre o governo e a população, como também usa a sua autoridade para exercer pressão sobre o Estado. Como refere Sanneh (1996, p. 96) a esse propósito, "os líderes políticos africanos perceberam que a religião e a política são fenômenos interligados, afetando-se mutuamente, recorrendo um ao outro e fazendo um apelo idêntico à confiança e lealdade".

Mas os conflitos na Nigéria têm criado, nas últimas décadas, um clima de desconfiança, de ódio e de intolerância religiosa. Cerca de $23 \%$ dos nigerianos estão preocupados com o extremismo levado a efeito por grupos muçulmanos. Segundo Laremont e Gregorian (2006, p. 28-30), o fato de a Nigéria ser hoje um Estado dividido é um legado colonial. Os britânicos contribuíram para a separação dos muçulmanos a Norte e os cristãos a Sul, governando as duas regiões de forma diferente. No Norte, a governação processou-se por meio de clérigos muçulmanos e de funcionários locais que não alteraram as práticas islâmicas, ao passo que, no Sul do país, foi instituída a cultura e os procedimentos britânicos. Por meio da administração indireta no Norte, os britânicos permitiram que o Islão permanecesse como uma força política e social. Depois da independência, os governadores dos estados do Norte permitiram a aplicação da lei da Sharia, pois consideraram que tinham algo a ganhar politicamente. Para além do ativismo sunita em defesa da aplicação da Sharia, as ordens xiitas começaram a emergir, levando a confrontos violentos entre cristãos e muçulmanos, criando tensões políticas e ameaçando a estabilidade do país. 
Desde a independência, a Nigéria tem permanecido como um Estado multiétnico, com vários grupos religiosos responsáveis pelos conflitos étnico-religiosos sob a forma de revoltas, sabotagens, assassinatos, lutas armadas, guerrilha e secessão, com implicações no desenvolvimento político e econômico do país (Salawu, 2010, p. 345).

As causas dos conflitos são multidimensionais e muitas residem em acusações de negligência, opressão, dominação, discriminação, marginalização, nepotismo e fanatismo e, sobretudo, na incapacidade dos líderes nigerianos em gerir e governar bem o país.

Na Nigéria, o crime organizado e os grupos extremistas violentos têm criado problemas de segurança complexos ao governo. Os ataques terroristas no Norte e no Sul do país envolvem jovens nigerianos cujas expectativas não foram correspondidas e cuja frustração potencia a agressão e a violência. A motivação para a militância inclui uma variedade de fatores étnicos e socioeconômicos para os quais não há soluções políticas fáceis. Há uma linha tênue entre o Estado e o sistema político oficial, por um lado, e os grupos rebeldes e a economia ilegal, por outro. Muitos políticos e militares estão ligados a grupos rebeldes, patrocinando e financiando-os, explorando as linhas de acesso à economia para melhorar ou redefinir o seu status político e poder (Campbell, 2010, p. 59).

É nesse difícil contexto político, econômico e social que surge a revolta do grupo Boko Haram em junho de 2009, procurando reforçar os elementos conservadores islâmicos ao impor uma variante violenta da ideologia religiosa islâmica em um Estado secular.

\section{O grupo Boko Haram: a insurgência}

O termo Boko Haram é a designação dada à organização terrorista nigeriana Jama’atu Ahlis Sunna Lidda'awati Wal-Jihad ou "pessoas comprometidas com a propagação dos ensinamentos do Profeta e Jihad" (Johnson, 2013). Pode ser traduzido como "a educação ocidental é proibida" e, segundo muitos especialistas, o 
conceito aponta para a rejeição do ensino secular e da civilização ocidental.

Criado em 2002 com caráter religioso, o grupo tornou-se insurgente quando Mohammed Yusuf, um jovem e carismático clérigo islamita nigeriano, assumiu o seu controle. Autodenominando-se de talibãs nigerianos, estabeleceram-se em uma área remota do Nordeste da Nigéria. O grupo rejeita a educação e a cultura ocidental e também a ciência moderna, defendendo, em alternativa, a difusão e a adesão ao Islão, procurando impor a lei da Sharia em todos os estados nigerianos (Bumah e Adelakun, 2009, p. 40).

A partir de 2009, o Boko Haram começa a envolver-se em conflitos violentos, protestando contra a pobreza, as desigualdades na educação, o desemprego crescente e a corrupção governamental (Ale, 2009, p. 8). Nesse mesmo ano, a morte do líder marca um ponto de viragem na atuação do grupo e força-o à clandestinidade. $\mathrm{O}$ Boko Haram surgiu mais violento e determinado à procura de vingança contra o Estado nigeriano pela execução do seu líder. Sob a liderança do imam Abubakar Shekau, os militantes levam a efeito deste, então, operações violentas contra alvos governamentais e religiosos, sobretudo no Norte do país. Para financiar as suas atividades, dedicam-se ao roubo de bancos e a raptos como fonte de rendimento por meio dos pedidos de resgate (Blanchard, 2012, p. 22). Alegadamente têm também ligações com indivíduos com poder e acesso a recursos vários, que as autoridades nigerianas têm procurado identificar (Forest, 2012, p. 71). O tráfico de armas e droga é ainda referido por Lauretta Napoleoni, especialista em financiamento do terrorismo, que afirma que o Boko Haram autofinancia-se por meio do tráfico de droga proveniente da América Latina. De acordo com Napoleoni, "nobody wants to admit that concaine reaches Europe via West Africa. This kind of business is a type of business where Islamic terrorist organizations are very much involved" (Napoleoni 2014 apud Caulderwood, 2014).

A ideologia do Boko Haram está envolta pela tradição do Islamismo, sendo uma das variantes do Islamismo radical que emergiu 
no Norte da Nigéria. Contudo, as suas crenças e ideias vão muito além da religião. Segundo Johnson (2013), o Boko Haram "é um sintoma de décadas de um governo falhado e de delinquência de elites que conduziu ao caos social". Também Isa (2010, p. 332) refere que "a ideia de Boko Haram não consiste só em rejeitar a educação ocidental. É um julgamento do seu falhanço, por não conseguir promover uma vida melhor".

O Boko Haram representa uma seita sunita islamita radical que encontra apoio entre as comunidades islâmicas sufistas da Nigéria, particularmente as irmandades Qadiriyya e Tijaniyya. Dada a sua ideologia antiocidental, o grupo tem ligação com extremistas sunitas ou grupos de terroristas como a Al-Qaeda ou afiliados, como a Al-Qaeda do Magrebe Islâmico (AQMI) e, mais recentemente, com o Estado Islâmico (ISIS). Essa proximidade ideológica com a Al-Qaeda surge em virtude de defenderem a ideia de que os políticos e a riqueza destruirão a pureza das sociedades islâmicas, por permitirem vícios como a prostituição, a pornografia e o álcool (Blanchard, 2014).

Segundo o relatório do Serviço de Pesquisa do Congresso dos Estados Unidos sobre a Nigéria de Lauren Ploch Blanchard (2014, p. 11), "os ataques do Boko Haram têm aumentado substancialmente em frequência e letalidade, através de ataques suicidas e engenhos explosivos improvisados". A esse propósito, a figura 1 ilustra bem o impacto crescente da ação do grupo na Nigéria. 
Figura 1 - Ação do Boko Haram na Nigéria

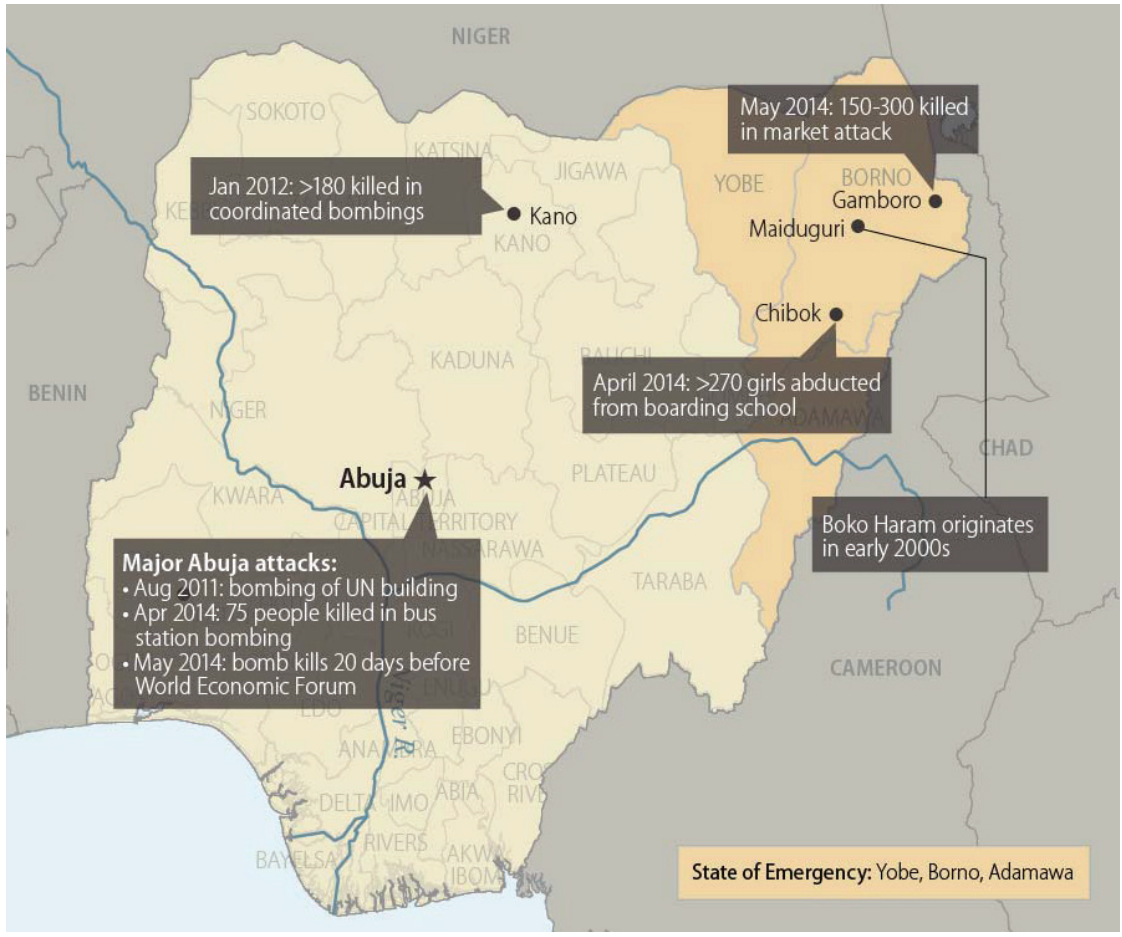

Fonte: Blanchard (2014, p. 5).

O modus operandi do grupo traz algumas semelhanças com os talibãs do Afeganistão, principalmente após a divulgação do envio de membros para campos de treino em países como a Argélia, o Afeganistão, o Paquistão, o Iraque e a Mauritânia (Alli, 2009, p. 1-8). Também a prova de atividade operacional do Salafish Group for Preaching and Combat da Argélia, dos Tablighi do Paquistão, dos missionários wahabitas da Arábia Saudita no Norte da Nigéria e o treino de alguns fundamentalistas nos campos de treino da Al-Qaeda provam que o Boko Haram tem ligações com grupos fundamentalistas em todo o mundo (op. cit.).

Segundo Hussein e Walker (2012), a metodologia do Boko Haram segue o caminho do radicalismo islâmico sunita do Afeganistão, do Iraque, do Paquistão e da Somália, forçando o terror contra tudo o 
que se opõe a um Estado Islâmico. Apesar de o governo nigeriano ter autorizado a Sharia em alguns estados do Norte, esse fato apenas veio inspirar uma maior militância ao grupo.

O Boko Haram pretende um Estado Islâmico. Não conferindo às leis seculares nenhuma validade, o grupo pretende espalhar o sectarismo para serem considerados “os guardiães do Islão", e não apenas muçulmanos que apoiam uma Nigéria unida.

Importa aqui distinguir terrorismo de fundamentalismo. A Resolução no 1566 do Conselho de Segurança das Nações Unidas indica como uma definição de terrorismo:

[...] criminal acts, including against civilians, committed with the intent to cause death or serious bodily injury, or taking of hostages, with the purpose to provoke a state of terror in the general public or in a group of persons or particular persons, intimidate a population or compel a government or an international organization to do or to abstain from doing any act (Nações Unidas, 2004).

Por sua vez, o terrorismo jihadista consiste em aterrorizar elementos civis de um determinado Estado, tendo por objetivo condicionar os decisores políticos na sua ação de luta contra o terrorismo, procurando a expansão da fé e da lei islâmica e instaurando, por meio do terror, uma ditadura islamita radical. $\mathrm{O}$ terrorismo praticado pelos movimentos muçulmanos assenta na doutrina islamita, sendo definido nos Estados Unidos e na Europa por "fundamentalismo islamita" ou mesmo "jihadismo". Nesse tipo de terrorismo há uma obediência rígida aos ensinamentos do Alcorão, que contempla o dever do fiel muçulmano de combater, por meio da violência, todos aqueles que não aceitam a palavra de Alá e que limitam o poder, a difusão e a expansão do Islamismo.

Os fundamentalistas islâmicos pretendem impor à força um sistema islâmico, que seja governado pela lei islâmica. $\mathrm{O}$ fundamentalismo apresenta-se como um fenômeno ameaçador da paz e da liberdade, ao defender o absolutismo ideológico caracterizado 
pela intolerância, pela opressão, pelos desvios políticos e pela limitação dos direitos individuais (Rodrigues, 1993, p. 98). Segundo Sutti e Ricardo (2003, p. 105), "os muçulmanos fundamentalistas são aqueles que concordam em matar os chamados infiéis, através da jihad e em nome da defesa dos princípios do Islão".

\section{As dificuldades do Estado no combate ao Boko Haram: que soluções?}

O grupo Boko Haram tem sido alvo de uma grande atenção por parte dos meios de comunicação social devido à violência e aos alvos/vítimas dos seus ataques. Inicialmente estes centravam-se geograficamente em quatro Estados nigerianos: Bauchi, Kano, Yobe e Borno, mas acabaram por adquirir um caráter mais nacional, ao chegarem à capital, Abuja.

Como resposta, o governo federal criou uma força especial com características militares em Maiduguri, no estado de Borno, composta por elementos do Exército, da Marinha, da Força Aérea, do Departamento de Segurança do estado e da Polícia nigeriana (Amnesty International, 2011, p. 30), com vista à rentabilização de recursos e à melhor fluidez de informação entre os serviços de segurança (The Economist, 2011, p. 56). Segundo A. J. Omede (2011), cerca de 30.000 efetivos do Exército e da Polícia foram para lá deslocados, nessa altura, para reforçar e controlar o "estado de emergência" decretado e lutar contra o Boko Haram. O governo fechou também as fronteiras entre o Norte da Nigéria e os estados vizinhos (Baldauf e Writer, 2012, p. 1) para impedir que elementos do grupo fugissem para os países vizinhos e recebessem ajuda dos grupos jihadistas estrangeiros que operam na região. No entanto, devido à dimensão das suas fronteiras, a capacidade do governo nigeriano tem sido limitada diante da ação do grupo.

Os esforços contraterroristas são marcados pela incapacidade da Polícia nigeriana em trabalhar a informação e efetuar investigações forenses (Solomon, 2012, p. 9), o que leva que algumas confissões sejam conseguidas sob tortura, possibilitando que muitos dos culpados escapem ao julgamento. As medidas contraterroristas 
são também contraproducentes devido à brutalidade perpetuada pelas forças de segurança que frequentemente cometem exageros.

Como refere Adesoji (2011, p. 112-113), “a resposta do governo ao fundamentalismo islâmico não parece ser adequada nem duradoura”. Por um lado, a ausência de equipamento e de fundos nos serviços de segurança dificulta uma ação eficaz contra o grupo. Por outro lado, a deficiente coordenação entre os diferentes serviços de segurança torna difícil o tratamento de informação relevante. Ao nível das forças de segurança, há ainda o receio de que alguns dos seus membros possam ser corruptos ou membros infiltrados do Boko Haram, pelo que esse problema pode ser mais grave.

A abordagem predominantemente militar para conter a ação terrorista perpetuada pelo Boko Haram continua gerando tensões entre o governo e a população local, sendo por isso necessário desenvolver uma estratégia diferente que implique significativas reformas políticas e de governação, aumentando significativamente a participação dos cidadãos na vida do Estado (Sampson, 2013 , p. 1). O Estado tem apostado na resposta armada à violência, por meio de operações conjuntas entre o Exército e a Polícia como resposta a incidentes específicos, assim como a adoção de estratégias de contraextremismo e radicalização. Nesse sentido, têm sido contratados clérigos islâmicos para pregar e ensinar um Islão moderado na rádio e na televisão, gerindo a percepção do público e evitando a radicalização da população vulnerável, em especial dos jovens (Okereke, 2012, p. 7).

Para além dessas estratégias, o governo desenvolveu também um quadro legislativo e da justiça criminal capaz de combater o extremismo do Boko Haram. Contudo, apesar desse reportório de estratégias operacionais e de governação, as tensões e controvérsias relativamente à adequação dessas medidas mantêm-se no país, sendo o Estado fortemente criticado (Sampson, 2013, p. 12-13).

As abordagens para terminar com a insurgência do Boko Haram divergem na Nigéria. Alguns defendem que a força tem de ser combatida com a força, e que o governo federal deve reorganizar e mobilizar a Polícia e as Forças Armadas juntamente às agências de 
segurança estrangeiras para terminar com as atividades do grupo. Outros sugerem o diálogo com o grupo, por meio de líderes de seitas religiosas e de Organizações Não Governamentais (ONGs) (Sampson, 2013).

Os problemas da segurança interna na Nigéria são complexos e têm sido agravados por uma gestão deficiente dos conflitos por parte do governo. Um dos problemas mais graves que o Estado nigeriano enfrenta consiste na violência étnico-nacionalista, nas revoltas religiosas e nos conflitos decorrentes da gestão dos recursos (Sampson, 2013, p. 38-41).

O futuro de uma boa governação e uma reforma do setor da segurança credível na Nigéria passa pela criação de uma constituição que aborde a natureza complexa das relações entre o governo e os grupos étnicos, a contenção da corrupção e o desenvolvimento de uma sociedade civil ativa e participativa. Têm sido efetuados esforços para modernizar o Exército, por meio da introdução de ideias democráticas, promover o diálogo entre a sociedade civil e os militares, bem como procurar sensibilizar os militares para a não intervenção em assuntos de caráter político.

Apenas a introdução de reformas socioeconômicas sustentáveis poderão reduzir a insatisfação da população e promover a estabilidade no país. O reforço do Estado, com uma melhor governação, garantindo o fornecimento de serviços básicos, como a educação, a saúde, o desenvolvimento de infraestruturas, promovendo a participação dos cidadãos a nível político, proporcionará a necessária legitimidade ao governo e é o melhor caminho para conter o extremismo religioso e o terrorismo no Norte da Nigéria. Como refere David Cook (2011, p. 89), "a resposta do governo nigeriano ao Boko Haram necessita de ser integrada numa estratégia política, econômica e de segurança que ofereça uma promessa de melhoria às populações do Norte e que limite o apelo do grupo e dos seus potenciais sucessores". O sucesso resultará da possibilidade de várias entidades trabalharem em conjunto, respeitando-se mutuamente e em conformidade com as leis e autoridades constituídas, porque sem paz e segurança não pode haver desenvolvimento sustentável. 


\section{Conclusão}

Tema de grande relevância atual, o fundamentalismo islâmico, nesse caso personificado por meio das atividades terroristas do grupo Boko Haram, suscitou a nossa atenção porque este surge em um contexto de Estado falhado. Apesar de tratar-se de um país rico em recursos minerais, a Nigéria apresenta indicadores de um Estado falhado em que a maior parte da população vive em um clima de total pobreza e degradação. É nesse contexto que grupos como o Boko Haram proliferam e acabam por ameaçar a segurança e o desenvolvimento econômico do Estado, questionando a sua autoridade.

Nesse quadro de instabilidade e de insegurança, apenas uma melhor governação do país, com a criação de emprego, a promoção do Estado de direito, a liberdade política e as oportunidades econômicas, bem como melhores infraestruturas na educação e na saúde, poderá combater a ação nefasta que o grupo Boko Haram provoca na sociedade e no Estado em geral.

A pobreza e o subdesenvolvimento, principalmente nos Estados muçulmanos, têm criado espaço para que grupos islamitas radicais, como o Boko Haram, prosperem, recorrendo a jovens desempregados e sem expectativas de futuro, que acabam por estar disponíveis para serem recrutados. A insurgência do grupo, que começou por ter motivações religiosas e que hoje é conhecido e classificado internacionalmente como terrorista, constitui uma ameaça crescente e real com a qual a Nigéria confronta-se e que certamente impedirá o Estado de alcançar um futuro estável. Com as eleições presidenciais em 2015, o Boko Haram intensificou a sua atividade, declarou apoio ao Estado Islâmico e expandiu a sua atividade aos Camarões, tendo como resultado o consequente reforço da unidade nacional, mas também originou um movimento anormal e significativo de deslocados nessa zona da África.

Com a aplicação da recente estratégia nacional de contraterrorismo e de um plano de revitalização da economia que ajude os mais afetados pela violência, bem como com a ajuda da comunidade internacional, talvez seja possível garantir o aparecimento 
de resultados positivos. Contudo, estes só serão possíveis com o trabalho conjunto das comunidades religiosas e das ONGs, assegurando programas de âmbito familiar, cultural e religioso que realcem os valores nacionais.

Estabelecer um processo de diálogo e angariar o apoio de setores muçulmanos mais moderados, com total respeito pelos direitos humanos, pode também contribuir para aumentar a proximidade étnica e religiosa. Muitos dos nigerianos estão insatisfeitos com o Estado nigeriano, considerado fonte de desigualdade e de corrupção, que falhou no cumprimento das suas mais elementares funções: segurança e bem-estar.

Para devolver a segurança à Nigéria, é necessário que todos se envolvam em melhorar o funcionamento do Estado, gerindo e aproveitando melhor as suas riquezas em proveito da população. Acreditamos que a resposta ao fenômeno extremista tem de ser dada em médio/longo prazo, de forma holística e robusta, combatendo as suas causas mais profundas e reforçando o aparelho do Estado.

O perpetuar do conflito entre o Estado nigeriano e o grupo Boko Haram, para além das consequências nefastas a nível econômico, tem também efeitos a nível humano, gerando refugiados e pessoas deslocadas, conflitos e tensões interétnicas, colocando em causa a unidade nacional. Esta é, assim, uma das questões que o Estado tem de resolver urgentemente. Só assim será possível iniciar novamente o caminho para a estabilidade e promover o desenvolvimento daquela que poderá vir a ser a maior potência da África Ocidental.

\section{Referências}

ADAWO, M. Poverty reduction in Nigeria: a necessary agenda. Current Research Journal of Economic Theory, v. 3, n. 1, p. 14-19, 2011.

ADESOJI, A. O. Between Maitatsine and Boko Haram: Islamic fundamentalism and the response of the Nigerian State. Africa Today, v. 57, n. 4, p. 98-119, 2011. 
ADOGAME, A. How God became a Nigerian: religious impulse and the unfolding of a nation. Journal of Contemporary African Studies, v. 28, p. 479-498, 2010.

ALE, A. Boko Haram: Soyinka Blames government. Saturday Punch, Lagos, 15 Aug. 2009. Disponível em: <http://journals. sub.uni-hamburg.de/giga/afsp/article/viewFile/330/330>. Acesso em: 10 dez. 2013.

ALJAZEERA.MuhammaduBuhari:Nigéria 'reduced toafailed state'. Aljazeera, 8 Feb. 2015. Disponível em: <http://www.aljazeera. com/programmes/talktojazeera/2015/02/muhammadubuhari-nigeria-reduced-failed-state-150208121316691.html > . Acesso em: 20 abr. 2016.

ALLI, Y. Revealed: Boko Haram leaders trained in Afghanistan, Algeria. The Nation, Lagos, 2 Aug. 2009. Disponível em: <http://journals.sub.uni-hamburg.de/giga/afsp/article/ viewFile/330/330>. Acesso em: 10 dez. 2013.

AMNESTY INTERNATIONAL. Nigeria: Human Rights Agenda 2011-2015. London: Amnesty International, 2011.

BALDAUF, S.; WRITER, S. Nigeria closes its borders amid unrest from Islamits, strikers. The Christian Science Monitor, 11 Jan. 2012. Disponível em: <http://www.csmonitor.com/World/ Africa/2012/0111/Nigeria-closes-its-borders-amid-unrestfrom-Islamists-strikers $>$. Acesso em: 14 dez. 2013.

BLANCHARD, L. P. Nigeria: current issues and US Policy. Washington: US Congressional Research Service, 2012. Disponível em: <http://www.hsdl.org/?view\&did=717882>. Acesso em: 14 jul. 2015.

. Nigeria's Boko Haram: frequently asked questions. Washington: US Congressional Research Service, 2014.

BUMAH, J.; ADELAKUN, A. The Boko Haram tragedy and other issues. The Punch, Lagos, 6 Aug. 2009. 
CAETANO, M. Manual de Ciência Política e Direito Constitucional. 6. ed. Coimbra: Almedina, 2014.

CAMPBELL, J. Nigeria. Dancing on the brink. 2nd ed. Maryland: Rowman \& Littlefield Publishers, 2010.

CAULDERWOOD, K. Fake charities, drug cartels, ransom and extortion: where Islamist group Boko Haram gets its cash. International Business Times, 16 May 2014. Disponível em: $<$ http://www.ibtimes.com/fake-charities-drug-cartels-ransomextortion-where-islamist-group-boko-haram-gets-itscash-1585743>. Acesso em: 14 jul. 2015.

COOK, D. Boko Haram: a prognosis. Texas: Rice University, 2011. EDEWOR, P. Corruption: the law in Nigeria. In: SOKEFUN, J. (Ed.). Corruption in Nigeria: a socio-cultural perspective. Ota: Covenant University, 2011.

FALOLA, T.; HEATON, M. A history of Nigeria. Cambridge: Cambridge University Press, 2008.

FOREIGN POLICY. Fragile States Index. Foreign Policy, 2015. Disponível em: <http:/foreignpolicy.com/2015/06/17/fragilestates-2015-islamic-state-ebola-ukraine-russia-ferguson/>. Acesso em: 20 abr. 2016.

FOREST, J. Confronting the terrorism of Boko Haram in Nigeria. Florida: The Jsou Press, 2012.

HAMZAT, A. Is Nigéria a failed state? (Part 1). The Nigerian Voice, 16 Mar. 2015. Disponível em: <http://www.thenigerianvoice. $\mathrm{com} /$ news/173382/1/is-nigeria-a-failed-state-part-1.html $>$. Acesso em: 20 abr. 2016.

HUSSEIN, B.; WALKER, L. Nigeria and the Sunni Islamic insurgency of Boko Haram: over 170 killed in Kano. Modern Tokyo Times, 2012. Disponível em: <http://moderntokyotimes. com>. Acesso em: 13 dez. 2013. 
IDOWU-FEARON, J. Conflict and cooperation between Christians and Muslims in Nigeria. In: BORDERLANDS LECTURE, 4., 2005, Durham. Annals... Durham: St. Johns College, 2005. Disponível em: <https://www.dur.ac.uk/resources/johns/ publications/conflict.pdf>. Acesso em: 17 dez. 2013.

IFOWODO, O. Debate: is Nigeria a failed State? BBC News, 7 Jul. 2009. Disponível em: <http://news.bbc.co.uk/2/hi/ africa/8112800.stm>. Acesso em: 20 abr. 2016.

IKE, D. Corruption and its impact on the economic development of Nigeria. Ota: Covenan University, 2009. Disponível em: $<$ http://eprints.covenantuniversity.edu.ng/663/>. Acesso em: 25 mar. 2013.

ISA, M. Militant Islamist groups in Northern Nigeria. In: OKUMU, W.; IKELEGBE, A. (Eds.). Militias, rebels and Islamist militants. Pretoria: Institute for Security Studies, 2010.

JACKSON, R.; SORENSEN, G. Introduction to international relations: theories and approaches. New York: Oxford University Press, 2007.

JOHNSON, T.; SERGIE, M. A. Boko Haram. Council on Foreign Relations, 2013. Disponível em: <http://www.cfr.org/nigeria/ boko-haram/p25739>. Acesso em: 13 dez. 2013.

LAREMONT, R.; GREGORIAN, H. Political Islam in West Africa and the Sahel. Military Review, p. 27-35, Jan.-Feb. 2006.

LUND, C. Twilight institutions: public authority and local politics in Africa. Development and Change, v. 37, n. 4, p. 685-705, 2006. MILLIKEN, J.; KRAUSE, K. State failure, State collapse, and State reconstruction: concepts, lessons and strategies. Development and Change, v. 33, n. 5, p. 753-774, 2002. 
NAÇÕES UNIDAS. Conselho de Segurança das Nações Unidas. Resolução $n^{\circ}$ 1566. Nova Iorque: Nações Unidas, 2004. Disponível em: <http://www.un.org/press/en/2004/sc8214. doc.htm>. Acesso em: 20 abr. 2016.

- Programa das Nações Unidas para o Desenvolvimento. Niger Delta Human Development Report. Nova Iorque: Nações Unidas, 2006. Disponível em: <http://web.ng.undp.org/reports/ nigeria_hdr_report.pdf $>$. Acesso em: 10 maio 2014.

.Human Development Report, Nigeria 2008-2009 "Achieving growth and equity" UN Abuja. Nova Iorque: UNDP, Nações Unidas 2008. Disponível em: http://planipolis.iiep.unesco.org/ upload/Nigeria/NigeriaHDR20082009.pdf [15 Abril 2013] . Highlights of our support during the year 2014 and how it helped the government and people of Nigeria. Nova Iorque: Nações Unidas, 2014. Disponível em: <http://www.ng.undp. org/content/nigeria/en/home/library/human_development/ undp-nigeria-annual-report-2014/>. Acesso em: 10 maio 2014. OKEREKE, N. E. Boko Haram crisis of July 2009: official response and public reactions. In: UCHENDU, E. (Ed.). New face of Islam in Eastern Nigeria and the Lake Chad Basin. Ibadan: Aboki, 2012.

OMEDE, A. J. Nigeria: analysing the security challenges of the goodluck Jonathan Administration. Canadian Social Science, v. 7, n. 5, p. 90-102, 2011.

ONWUKA, E. Oil extraction, environmental degradation and poverty in the Niger Delta region of Nigeria: a viewpoint. International Journal of Environmental Studies, v. 62, n. 6, p. 655-662, 2005.

OTITE, O. Themes in African social and political thought. Nigeria: Fourth Dimension Publishing Company, 2000. 
PEW RESEARCH CENTER. Table: religious composition by country, in percentages. Pew Research Center, 18 Dec. 2012. Disponível em: <http://www.pewforum.org/2012/12/18/tablereligious-composition-by-country-in-percentages/>. Acesso em: 10 maio 2014.

RISSE, T. Governance without a state? New York: Columbia University Press, 2013.

RODRIGUES, S. Contributo para a interpretação do fundamentalismo islâmico. Lisboa: Lisboa: Instituto de Defesa Nacional, 1993. (Relatório n. 68).

ROTBERG, R. When States fail: causes and consequences. New Jersey: Princeton University Press, 2003.

SALAWU, B. Ethon-religious conflicts in Nigeria: causal analysis and proposals for new management strategies. European Journal of Social Sciences, v. 13, n. 3, p. 345-353, 2010.

SAMPSON, I. T. The dilemmas of counter-bokoharamism: debating state responses to Boko Haram terrorism in Northern Nigeria. Security Journal, p. 1-25, 2013.

SANNEH, L. Piety \& power Muslims and Christians in West Africa. New York: Orbis Books, 1996.

SOLOMON, H. Counter-terrorism in Nigeria. The Rusi Journal, v. 157, n. 4, p. 6-11, 2012.

SOUSA, M. R. Direito Constitucional. Braga: Livraria Cruz, 1978.

SUTTI, P.; RICARDO, S. As diversas faces do terrorismo. São Paulo: Harbra, 2003.

THE ECONOMIST. Nigeria's new government: one and a half cheers for the economy - none for security. The Economist, 12 Nov. 2011. Disponível em: <http://www.economist.com/ node/21538207>. Acesso em: 16 dez. 2013. 
TRANSPARENCY INTERNATIONAL. Nigeria's corruption challenge. Transparency International, 28 May 2015. Disponível em: <http://www.transparency.org/news/feature/nigerias_ corruption_challenge $>$. Acesso em: 27 jul. 2015.

TITECA, K.; HERDT, T. Real governance beyond the "failed state": negotiating education in the Democratic Republic of the Cong. African Affairs, v. 110, n. 439, p. 213-231, 2011.

\section{Resumo}

A atual situação na Nigéria motiva uma reflexão sobre o Estado e as funções que este desempenha na sociedade. O incremento do fundamentalismo islâmico no país surge em um contexto de problemas estruturais complexos que colocam em causa a autoridade e a legitimidade do Estado. A evidente fragilidade das instituições e a fraca resposta por parte do Estado à instabilidade e à insegurança provocada por grupos extremistas como o Boko Haram, leva-nos a questionar se a Nigéria poderá ser considerada um Estado falhado. E, tratando-se de um Estado falhado em que a segurança interna é deficitária e os conflitos interétnicos proliferam, estará a unidade nacional comprometida ou seriamente ameaçada? Neste artigo tentamos aferir, por um lado, até que ponto o fundamentalismo islâmico tem afetado o desenvolvimento econômico e humano na Nigéria e, por outro, como o governo tem lidado com esse problema.

Palavras-chave: Nigéria; Estado falhado; fundamentalismo islâmico; Boko Haram; terrorismo.

\section{Abstract}

The current situation in Nigeria motivates a reflection on the State and the functions it plays in society. The rise of Islamic fundamentalism in the country arises in a complex context of structural problems that puts in question the authority and legitimacy of the State. The clear weakness of institutions and the fragile response by the State to instability and insecurity caused by extremist groups such as Boko Haram, leads us to question whether Nigeria can be considered a 
failed State. And in the case of a failed State where internal security is in deficit and interethnic conflicts proliferate, will national unity be compromised or seriously threatened? In this article we try to assess the extent to which Islamic fundamentalism has affected the human and economic development in Nigeria and examine how the government has tried to solve the problem.

Keywords: Nigeria; Boko Haram; failed state; conflict.

Recebido em 6 de agosto de 2015.

Aprovado em 13 de setembro de 2016. 